\title{
Carreiras Políticas na Câmara dos Deputados: Uma Análise Quase-Experimental
}

\author{
Fernando Meireles \\ Doutor em Ciência Política pela Universidade Federal de Minas Gerais (UFMG) e Pós-Doutorando no \\ Instituto de Estudos Sociais e Políticos (IESP-UERJ). Pesquisador do Observatório do Legislativo Brasileiro \\ (OLB). Rio de Janeiro, RJ. Brasil. \\ E-mail: fernando.meireles@iesp.uerj.br, http:/ / orcid.org/0000-0002-7027-2058
}

\section{INTRODUÇÃO}

$\mathrm{O}$

cupar um cargo eletivo pode trazer vantagens a quem deseja fazer carreira na política. Tanto nos Estados Unidos quanto em outros países, incumbentes têm chances muito maiores de vencer eleições vis-à-vis seus concorrentes, seja por se valerem de recursos públicos para obter votos, por terem maior acesso à mídia e doações de campanha, ou ainda por desfrutarem de influência considerável no processo legislativo (Ansolabehere et al., 2000; Eggers et al., 2015; Fowler e Hall, 2017). Por sua vez, esta vantagem acaba se desdobrando em outro aspecto: quase todos os incumbentes, nestes locais, disputam a reeleição ao término dos seus mandatos e, em parte por esta vantagem eleitoral que possuem, a maior parte é bem-sucedida. Desse modo, não raro alguns deles acabam acumulando longos anos de vida pública e ocupando cargos influentes dentro da estrutura legislativa (Epstein et al., 1997).

É plausível supor que o mesmo ocorra no Brasil - afinal, aqui os parlamentares também têm acesso a cargos, verba para exercício e divulgação do mandato, prerrogativa de emendar o orçamento para destinar obras e serviços aos seus eleitores, entre outros recursos que poderiam tornar atrativo o desenvolvimento de carreiras longas. Mas ao menos no que diz respeito à Câmara dos Deputados, uma parcela importante da literatura sustenta o contrário: as carreiras legislativas no Brasil não seriam tão extensas quanto nos Estados Unidos, e os incentivos para permanecer na Câmara não seriam a principal motivação dos deputados brasileiros - pelo menos não em longo prazo (Samuels, 2000, 2001, 2003). 
De acordo com dados compilados por Samuels (2003), quase um terço dos deputados eleitos nos períodos democráticos entre 1945 e 1998 sequer disputou a reeleição. Entre os que tentaram, apenas cerca de $60 \%$ foram bem-sucedidos. A explicação disto, segundo Samuels, residiria principalmente no efeito conjunto dos sistemas proporcional com lista aberta e federativo descentralizado. Em primeiro lugar, incumbentes que tentam a reeleição têm incentivos para competir com seus colegas de nominata, já que precisam fazer mais votos do que estes para melhorar suas colocações dentro das listas caso queiram ser eleitos. Por outro lado, isso seria difícil porque a ausência de mecanismos de controle no recrutamento de candidatos impediria os incumbentes de barrar candidaturas de seus rivais. Em segundo lugar, a disponibilidade de cargos executivos municipais, que contam com maiores prerrogativas e recursos, atrairia esses incumbentes: como podem disputar as eleições municipais no meio de seus mandatos sem o risco de perdê-los, seriam incentivados a sair da Câmara. Um congresso centralizado, que concentra no Colégio de Líderes, na Mesa Diretora e nas presidências das Comissões Permanentes a maior parte dos poderes de agenda, e que dá pouco espaço para a atuação parlamentar individual, completa este cenário.

Em que pesem esses argumentos, a tese de que a Câmara funcionaria como um "trampolim" para outros cargos deixa diversas lacunas sem explicação. Com dados que cobrem maior período, Santos e Pegurier (2011) afirmam, em contraponto a Samuels, que o fluxo das carreiras na Câmara não segue padrão claramente executivo: um número considerável de deputados disputa eleições para as Assembleias, outros ainda assumem cargos burocráticos e - o que é ainda mais sintomático da falta de linearidade das carreiras no Brasil - vários acabam retornando à Câmara depois disso. Como defendem os autores, esses dados demonstram que o padrão de carreiras no Brasil não se conforma ao modelo sugerido por Samuels, segundo o qual existiria uma hierarquia entre os cargos eletivos disponíveis, com os executivos subnacionais sendo geralmente mais visados. Mais que isso, esses dados apontam para a centralidade da Câmara dos Deputados na estrutura de oportunidades do sistema político brasileiro, uma vez que passam por ela desde políticos em início de carreira até futuros ministros e presidentes, muitos dos quais acabam retornando a ela posteriormente. 
A principal contribuição deste artigo é oferecer uma perspectiva alternativa para examinar essa questão. Especificamente, meu objetivo é investigar o efeito de vencer uma eleição para a Câmara dos Deputados sobre a carreira política de um candidato, isto é, o efeito que decorre exclusivamente da ocupação de uma vaga nesta Casa. Com esse fim, procuro avançar em relação aos estudos que analisam as decisões de deputados em exercício ao tomar as carreiras dos candidatos que disputam eleições para a Câmara como objeto de análise. Essa mudança de foco me permite examinar o efeito que obter um mandato legislativo tem sobre a carreira futura de um político, tanto em termos de ambição (quais cargos os incumbentes passam a disputar), quanto de sucesso (quais cargos eles obtêm). Com isso, teremos mais clareza a respeito do papel que a câmara baixa exerce na formação dos padrões de carreiras políticas no Brasil. Como milhares de candidatos a deputado federal investem tempo e recursos na tentativa de serem eleitos, obviamente esperam obter algo com isso. A análise que segue procura justamente mostrar o que está em jogo no horizonte de carreira destes candidatos.

Examinar o efeito de ser eleito para a Câmara, contudo, envolve superar um maior problema: o de endogeneidade. Dito de forma simples, candidatos que vencem uma eleição geralmente são diferentes dos derrotados em características relacionadas ao desempenho nas urnas, como influência pessoal, carisma e acesso a fontes de financiamento. Compará-los, portanto, pode levar-nos a concluir que obter um mandato tem efeitos positivos sobre a carreira de um candidato mesmo que o cargo de deputado não traga benefício algum (Ansolabehere et al., 2000; Erikson, 1971; Gelman e King, 1990). A principal implicação disso é que, mesmo controlando outros fatores relacionados ao desempenho eleitoral por meio de regressão multivariada, é difícil distinguir o efeito de ser incumbente dos fatores que levam um candidato a vencer uma primeira eleição. Por essa razão, outra abordagem é necessária.

A abordagem utilizada neste artigo é uma quase-experimental: a regressão descontínua. Como diferenças pequenas de votos entre dois candidatos geralmente podem ser consideradas aleatórias, já que eles não controlam exatamente quantos votos receberão, comparo candidatos que quase venceram com outros que quase perderam as eleições dentro das listas partidárias para estimar o efeito causal de ser eleito para a Câmara. Adotando a terminologia do modelo de re- 
sultados potenciais de Rubin (1974), a ideia é considerar os grupos de candidatos eleitos e não eleitos como de tratamento e controle, respectivamente, e observar o efeito independente de dar cargos de deputado a uns, e não a outros, no desenvolvimento de suas carreiras políticas. Essa abordagem me permite identificar o efeito causal de obter um mandato, satisfeitos alguns pressupostos.

Os resultados mostram que obter um mandato na Câmara causa um impacto substantivo na carreira de um candidato. Em média, os eleitos passam a ambicionar mais a disputa pelo mesmo cargo novamente e, além disso, são cerca de 25 pontos percentuais mais bem-sucedidos do que seus contrafactuais - algo semelhante ao que ocorre em países com outros sistemas eleitorais (Eggers et al., 2015, 2014; Fowler e Hall, 2017; Lee, 2008). Com uma base de dados que cobre todas as eleições desde 1998, mostro que os eleitos também têm maior probabilidade de disputar e vencer eleições para a Câmara mesmo 12 anos depois. Por si só, esses resultados mostram que obter o cargo de deputado federal faz diferença positivamente na carreira futura de um candidato, significando alterações não desprezíveis no tipo de ambição e nas chances de vencer novas eleições tanto no curto quanto no longo prazo.

Inversamente, candidatos derrotados em uma eleição apertada para a Câmara dos Deputados passam cada vez mais a abdicar de concorrer novamente a esse cargo. Seus tipos de ambição deslocam-se principalmente para o nível local: passam a ser mais propensos a disputar eleições municipais dois anos depois. Mesmo assim, têm pouco sucesso se comparados aos incumbentes, o que se reflete nas suas taxas de aposentadoria: candidatos derrotados por poucos votos têm probabilidade de cerca de 9 pontos percentuais a mais de não concorrer a nenhum outro cargo eletivo nos próximos 12 anos. Para estes, mesmo uma única derrota, ainda que por poucos votos, pode significar abrir mão de novas candidaturas.

De forma geral, meus resultados corroboram a influência da Câmara dos Deputados na formação dos padrões de carreira no Brasil (Santos e Pegurier, 2011). Enquanto candidatos derrotados têm chances muito menores de se recandidatar e de vencer a disputa pelo mesmo posto no futuro, vencedores passam a ambicionar mais a reeleição e, o que é mais importante, ter maior probabilidade de obtê-la. Apesar de a validade externa dos resultados não permitir traçar generaliza- 
ções a respeito dos candidatos que venceram com margens maiores de votos, o fato de os incumbentes mais vulneráveis eleitoralmente terem benefícios substantivos ao obter um mandato sugere que, no mínimo, este efeito deve ser igual ou maior para os candidatos mais bem votados. Desse modo, o artigo contribui ao mostrar que os resultados de uma única eleição podem ter efeitos substantivos nos padrões de carreira de um sistema como o brasileiro, seja incentivando uma ambição estática para uns, direcionando outros para o nível local, ou mesmo impelindo à renúncia de concorrer em novos pleitos. O artigo procede da seguinte forma: na próxima seção, reviso alguns estudos sobre os incentivos de carreira na Câmara para, então, discutir o problema empírico de analisar o efeito de ser incumbente sobre a carreira de um político. Em sequência, apresento o desenho de pesquisa utilizado e mostro como ele supera este problema. Por fim, seguem os resultados e as conclusões da pesquisa.

\section{ELEIÇÃO E REELEIÇÃO NA CÂMARA}

\section{Incentivos de carreira na Câmara dos Deputados}

Observando as taxas de renovação parlamentar na Câmara dos Deputados, a principal conclusão que se depreende é que não é fácil para os deputados brasileiros manter seus cargos. Na eleição de 2010, por exemplo, apenas $72 \%$ dos 604 deputados que exerceram o cargo, inclusos suplentes que tomaram posse, disputaram a reeleição (Pereira e Rennó, 2013). Mais ilustrativo, contudo, é que desse total apenas 66\% permaneceu na Câmara na legislatura seguinte. Comparativamente, esta taxa de permanência é menor do que a observada em outros países - ainda que, como sustentam Leoni et al. (2003), esteja acima da média na América Latina.

De acordo com Samuels (2003), dados como estes sugerem algo sobre os incentivos que orientam as carreiras dos deputados brasileiros. Ao decidir se candidatar, avaliam o que podem ganhar permanecendo em seus cargos, os custos de disputar a reeleição, e as chances de sucesso. No caso brasileiro, esse procedimento os levaria a concluir que ocupar cargos executivos tende a oferecer benefícios maiores que a permanência na casa baixa; e que existe risco elevado de perder a disputa pela reeleição. Em outras palavras, a Câmara dos Deputados não seria o destino final de carreira dos deputados brasileiros. 
Por um lado, a estrutura de oportunidades, definida pelos postos eletivos à disposição nos diferentes níveis de governo, colocaria ênfase nos cargos executivos, uma vez que estes contam com prerrogativas mais importantes, como a de influir na composição e distribuição de recursos orçamentários, e a de fazer indicações para cargos públicos (Samuels, 2000, 2003). O fato das eleições nacionais e municipais serem realizadas separadamente, com diferença de dois anos, permite que os incumbentes na Câmara disputem eleições no meio de seus mandatos. E mesmo que não sejam eleitos para governar um município, ainda têm a possibilidade de disputar outra eleição nacional dois anos depois, ou de buscar cargos subnacionais de livre nomeação. Portanto, pelo baixo risco e pelos altos benefícios envolvidos, as carreiras políticas dos deputados penderiam para os executivos municipais, ao menos no longo prazo.

Essa atração para cargos executivos encontra reforço em três fatores: a elevada competição intrapartidária, e a baixa capacidade de reivindicar crédito e de influenciar o processo legislativo dificultariam tentativas de reeleição. Como os dois primeiros incentivam a competição individual, e como a maioria dos líderes partidários carece de recursos para controlar as candidaturas, os partidos perderiam capacidade de coordenar o processo eleitoral (Ames, 1995). Por conta disto, mesmo que os partidos desejassem manter seus membros eleitos nos mesmos cargos, é o cálculo de riscos vs. benefícios que acaba determinando as altas taxas de renovação parlamentar na Câmara dos Deputados (Samuels, 2008).

De maneira mais ampla, estes incentivos também poderiam produzir o resultado agregado de impedir a institucionalização da Câmara (Samuels, 2003:111). Se, como Mayhew (1974) argumenta para o caso americano, congressos são organizados para facilitar a reeleição de seus ocupantes, o fato de a ambição dos deputados brasileiros ser direcionada para cargos executivos lhes retiraria incentivos para promover melhorias no legislativo. Dessa forma, sem contar com prerrogativas importantes, deputados teriam pouca capacidade de influir no policy-making para atender seus eleitores. $\mathrm{O}$ efeito final disto seria circular: deputados não têm incentivos para buscar a reeleição, e por isso não procuram institucionalizar a Câmara; e, pela falta de institucionalização, têm poucos incentivos para permanecer nela. Segundo Samuels (2003), isto fica evidente no papel exercido pelo Legislativo na formulação e aprovação das leis orçamentárias anuais (LOA), nas 
quais os parlamentares dispõem de limites no número de emendas que podem fazer, bem como no valor total que podem levar aos seus redutos por meio delas. Dependem, ainda, da boa vontade do Executivo para executá-las ${ }^{1}$.

O cenário descrito por esta perspectiva é claro: obter a reeleição seria algo difícil e, por consequência, incumbentes não seriam incentivados a buscá-la. Ao contrário, os deputados teriam ambições progressivas, isto é, incentivos para disputar cargos mais importantes fora da Câmara - especialmente subnacionais. Os poucos que disputariam a reeleição seriam aqueles com pior desempenho eleitoral, para os quais vencer eleições executivas seria menos factível. De forma agregada, isso contribuiria para diminuir as taxas de sucesso na reeleição na Câmara dos Deputados: se apenas incumbentes menos qualificados tentam a reeleição, e se os mais qualificados priorizam outros postos, inevitavelmente a renovação legislativa aumenta (Samuels, 2003).

Mas até que ponto esta tese dá conta de explicar a dinâmica da reeleição e dos padrões de carreira dos deputados federais no Brasil? A literatura sobre o tema vem crescendo nos últimos anos e, em particular, coloca nuances importantes sobre ela. Grosso modo, o argumento geral desses estudos é que a sorte eleitoral dos incumbentes não pode ser deduzida diretamente do arranjo institucional brasileiro, especificamente dos sistemas eleitoral e federativo. Deputados teriam espaços de manobra para diminuir os riscos de concorrer à reeleição ou a outros cargos (Leoni et al., 2003; Pereira e Rennó, 2001, 2013). Além disso, segundo Santos e Pegurier (2011), o número de incumbentes que tentaram a reeleição vem crescendo, tendo passado de cerca de $70 \%$ em 1990 para quase $85 \%$ em $2006^{2}$. Outros estudos ainda mostram variação considerável entre as escolhas de carreira dos deputados brasileiros, tornando mais apropriado o uso de um modelo integrado de carreiras políticas (Borchert, 2011), que considera os frequentes movimentos entre níveis da federação. Isso inclui também disputar eleições majoritárias municipais no meio dos mandatos -, que refletem as diferentes condições de competição em cada distrito, e entre poderes (Legislativo e Executivo), sem estabelecer caminhos fixos de carreira (Santos e Pegurier, 2011; Graça e Souza, 2014).

Pereira e Rennó (2013), por exemplo, analisam os fatores associados com a decisão de buscar a reeleição entre incumbentes, inclusos os suplentes que tomaram posse, de 1998 a 2010. De acordo com seus 
resultados, deputados têm probabilidade maior de vencer a reeleição do que de obter outros cargos e, por isso, mesmo sendo pouco atrativa, uma carreira na Câmara acaba sendo uma opção segura para incumbentes que avaliam ter poucas chances de conquistar postos mais importantes. Similarmente, Pereira e Rennó $(2001,2007)$ investigam as estratégias de reeleição dos deputados brasileiros, mostrando que diversos fatores influenciam este resultado, em especial aqueles ligados ao atendimento de demandas locais (sobretudo executar emendas orçamentárias), e ao efeito das eleições presidenciais. Estas dariam incentivos aos presidentes que buscam a reeleição para distribuir mais recursos aos deputados de sua coalizão, mas não aos presidentes em final de mandato. Juntas, estas conclusões sugerem que altas taxas de reeleição e baixos incentivos para permanecer no mesmo cargo não são incompatíveis. Fundamentalmente, a decisão de buscar a reeleição depende dos custos de optar por outros postos disponíveis, bem como dos recursos que os incumbentes são capazes de mobilizar para investir em suas carreiras.

Também deve ser considerado que a competição eleitoral enfrentada por um deputado que tenta a reeleição quase nunca é a mesma dos demais. O número de vagas de cada distrito, o número de candidatos competitivos dentro e fora das listas eleitorais, e a capacidade das listas eleitorais de captar votos podem afetar drasticamente as chances de obter a reeleição. Nos casos de Roraima, Rondônia, Sergipe, entre outros, conquistar uma das oito vagas para a Câmara exige captar relativamente muito mais votos do que para se eleger numa das respectivas assembleias estaduais. Isto é, o quociente eleitoral é consideravelmente mais elevado para a Câmara. Em decorrência disso, maior magnitude eleitoral tende a elevar gastos de campanha e a desconcentrar os votos dos eleitos (Lemos et al., 2010; Silva, 2017), além de exigir maior coordenação na formação das listas partidárias e das coligações proporcionais - visando evitar que candidatos desafiantes tomem as cadeiras dos incumbentes. Confrontado com a opção de disputar uma daquelas oito vagas numa lista com outros candidatos fortes eleitoralmente, portanto, a opção mais segura para um deputado em final de mandato pode ser "ambicionar" um cargo menos atrativo, mesmo que permanecer na Câmara seja o mais desejado.

Este aspecto da escolha de carreira dos deputados também é matizado pelo alinhamento entre níveis de governo. Borges e Sanches (2016) argumentam que a ambição dos deputados brasileiros depende do 
status governamental de cada um. Como presidentes e governadores controlam recursos fundamentais para o desenvolvimento de suas carreiras, os que integram coalizões de governo nos níveis nacional e estadual têm maiores chances de buscar a reeleição, especialmente quando acumulam mais de um mandato. Para estes deputados, isso significa contar com maior boa vontade do executivo nacional e estadual para liberar verbas para seus redutos eleitorais, ou ainda a possibilidade de assumir cargos de relevo dentro da estrutura legislativa, que lhes dão maior visibilidade e capacidade de influir no processo legislativo. Permitem também expandir suas votações pelo território e dominar mais municípios - efeito que seria independente do valor intrínseco ao cargo de deputado (Borges et al., 2016). Por outro lado, deputados oposicionistas nos dois níveis são mais propensos a disputar cargos mais importantes, já que suas reeleições são incertas e suas perspectivas dentro da Câmara, piores. Apenas para estes deputados a tese de Samuels (2003) é corroborada.

Apesar dos avanços que representam em relação ao trabalho original de Samuels (2003), estes argumentos expostos acima deixam de lado outras questões não menos importantes. Ao comparar apenas deputados em exercício, estes estudos limitam seus escopos à reeleição, não abarcando o fenômeno anterior e mais amplo que é a eleição, isto é, a competição por uma vaga na Câmara entre todos os candidatos. Nesse ponto, a literatura sobre a Câmara contrasta frontalmente com a tradição americana de estudos sobre reeleição, em que o principal aspecto de interesse recai sobre a chamada vantagem dos incumbentes, que representa a diferença no desempenho eleitoral de candidatos que tentam a reeleição vis-à-vis candidatos desafiantes (Ansolabehere et al., 2000; Erikson, 1971; Fowler e Hall, 2017; Gelman e King, 1990). Por exemplo, no caso da House americana, Fowler e Hall (2017) mostram que partidos vencedores em eleições distritais apertadas têm cerca de 50\% mais probabilidade de também vencer a eleição dois anos depois - efeito que diminui, mas se mantém positivo, por até 16 anos. No Brasil, ao contrário, apenas recentemente alguns estudos compararam os desempenhos dos candidatos mostrando que, assim como nos EUA, incumbentes têm tanto mais chances de serem eleitos quanto maior número de votos (Perissinotto e Miríade, 2009; Speck e Mancuso, 2014).

Embora isso seja algo difícil de analisar no caso brasileiro por conta da combinação entre lista aberta e uma complexa estrutura de 
oportunidades, é possível avançar nesse ponto partindo de outra perspectiva. É razoável supor que a maioria dos candidatos que concorrem a uma vaga na Câmara têm expectativas sobre os benefícios oriundos exclusivamente do cargo, mas estes incentivos são mantidos constantes nas análises que comparam apenas incumbentes. Se deputados têm ambições diferentes de outros políticos, obter um mandato na Câmara pode influenciar as estratégias de carreira de seus ocupantes. Candidatos eleitos passam a contar com todas as prerrogativas do cargo de deputado federal, que alteram suas percepções de risco e benefícios de disputar eleições futuras; e isso, de forma agregada, afetará os padrões de carreira do sistema político como um todo. Sendo este o caso, teremos indícios de que incumbentes, também aqui no Brasil, desfrutam de vantagens ao menos carreira futura. Como dito anteriormente, investigar esta questão é o objetivo deste artigo, mas, para atingi-lo, é necessário lidar antes com um problema empírico maior.

\section{0 problema de endogeneidade}

Se candidatos avaliam a probabilidade que têm de serem eleitos quando decidem disputar um cargo eletivo, comparar os desempenhos posteriores de candidatos perdedores com vencedores pode gerar viés de seleção amostral, uma vez que os perdedores podem antecipar derrotas e decidir não concorrer. E, mesmo que a maioria dos candidatos, entre eleitos e derrotados, dispute novamente a mesma eleição, estes podem ser diferentes. Como aqueles que já venceram eleições possuem características correlacionadas com seus desempenhos eleitorais (carisma, experiência, redes de financiamento, entre outros), é difícil distinguir se incumbentes se saem melhor no futuro por causa de seus cargos ou por causa dessas características - que já os levaram a vencer uma primeira eleição anteriormente (Erikson, 1971). Dito de outro modo, comparar incumbentes e não incumbentes, para analisar o efeito do mandato sobre suas carreiras pode ser o mesmo que comparar laranjas com maçãs.

Tradicionalmente, os estudos sobre o tema lidam com estes problemas por meio de regressões multivariadas. A solução, neste caso, consiste em incluir nos modelos todas as variáveis que possam influir na relação de interesse, bloqueando os caminhos alternativos que levam de X a Y (Morgan e Winship, 2014). Contudo, esta estratégia é normalmente falha: é praticamente impossível contro- 
lar todos os fatores que possam influenciar $Y$ através de $X$, seja por falta de dados, dificuldade de controlar fatores não observados, ou por não saber ex ante tudo o que deve ser controlado. Por conta disso, o pressuposto de que não existe correlação entre variáveis independentes e o termo de erro é violado, enviesando as estimativas obtidas.

Uma simulação ajuda a ilustrar o problema. Suponhamos que apenas duas variáveis influenciem a probabilidade de eleição de um candidato $i$ : Carisma, variável contínua com distribuição normal que varia de 0 a 100, em que 100 indica um candidato com o máximo de carisma possível; e Incumbência, indicador binário que assume o valor de 1 para candidatos incumbentes e 0 para desafiantes. Suponhamos ainda que estas duas variáveis têm correlação de Pearson de 0,2 entre elas, sugerindo que ser incumbente está associado positivamente com carisma. Neste exemplo, a probabilidade de um candidato vencer uma determinada eleição poderia ser modelada como

$$
Y_{i}=\alpha+\beta \text { Incumbencia }_{i}+\gamma \text { Carisma }_{i}+\varepsilon_{i}
$$

em que $Y_{i}$ indica se o candidato $i$ foi eleito (1) ou não (0). Para exemplificar como a endogeneidade entre Incumbência e Carisma afeta as estimativas obtidas num modelo de Mínimos Quadrados Ordinários (MQO), defino que o efeito da incumbência é 0 (isto é, ser incumbente não traz efeito algum), e que cada ponto a mais de carisma aumenta em $1 \%$ a probabilidade de um candidato ser eleito. Adicionalmente, defino a constante como igual a 1 , e o termo de erro como 0 , com distribuição normal. Com estes parâmetros foram simuladas 2.000 regressões MQO com dados gerados aleatoriamente ${ }^{3}$. Em 1.000 destas regressões, apenas a variável Incumbência foi incluída no modelo, para captar o efeito de ser incumbente sobre a probabilidade de se eleger; nas outras 1.000 regressões, Carisma também foi incluída. As distribuições dos coeficientes estimados da incumbência estão no Gráfico 1, e mostram os resultados da simulação. 
Gráfico 1

Efeito da endogeneidade sobre as estimativas de um modelo linear

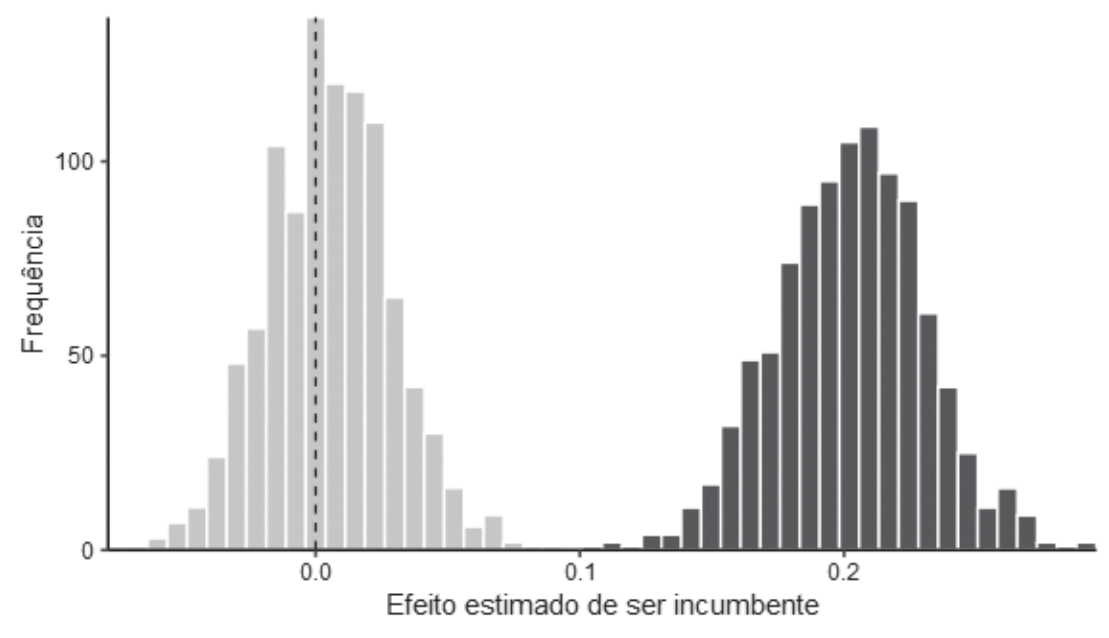

Sem Endogeneidade

Com Endogeneidade

Fonte: Elaboração própria, com base em simulações computacionais.

Resumidamente, quando ambas as variáveis são incluídas no modelo, não há problema de endogeneidade: a variável Incumbência retorna, em média, o efeito esperado: 0 . Ao contrário, quando Carisma não é incluído no modelo, esta passa para o termo de erro (como variável não observada). Com isso, a estimativa do efeito da incumbência torna-se enviesada, retornando em média-efeito positivo de cerca de 0,2 (idêntico à correlação entre incumbência e carisma definida anteriormente), indicando que incumbentes têm maior probabilidade de serem eleitos do que não incumbentes - quando sabemos que esse não é o caso. Embora seja um exercício simples, ele ilustra o potencial de endogeneidade aqui envolvido: diversos fatores normalmente estão associados à conquista de um cargo eletivo e ao desempenho eleitoral futuro de um candidato, de forma que a ausência deles nos modelos enviesa as estimativas do efeito de ser incumbente sobre outros fatores.

Problemas como esses constituem um debate mais amplo nas $\mathrm{Ci}$ ências Sociais contemporâneas. Embora perguntas de pesquisa frequentemente hipotetizem relações causais, do tipo $X \rightarrow Y$, métodos correlacionais não permitem respondê-las sem que se assumam pressupostos pouco plausíveis - como o de que não existem variá- 
veis omitidas correlacionadas às variáveis incluídas e a dependente (Dunning, 2012; Morgan e Winship, 2014). Outros autores vão além, sugerindo que "(...) no amount of econometric or statistical modeling can make the move from correlation to causation persuasive" (Sekhon, 2009:503). O que é proposto como solução ao problema de identificação causal, nestes casos, é adoção de desenhos experimentais e experimentos naturais. Esse é o caminho que adoto para examinar os efeitos de obter um mandato na Câmara na carreira dos políticos brasileiros.

\section{DESENHO DE PESQUISA}

\section{Estratégia de Identificação: Regressão Descontínua}

O objetivo deste artigo é investigar como a ocupação de um cargo na Câmara afeta, sozinha, a carreira de um político. Apesar de parecer simples, fazer isso pressupõe lidar com uma maior dificuldade: candidatos com mais recursos e características desejáveis aos eleitores normalmente são eleitos e, pelas mesmas razões, tendem a serem reeleitos. Isso significa que é necessário isolar a obtenção de mandato de outros fatores relacionados para estimar o efeito causal de ser incumbente. Embora não possamos fazer isso diretamente, sorteando quem se tornará deputado por meio de um experimento, podemos explorar determinadas características das eleições que emulam esse procedimento. É aqui que entra o desenho de pesquisa adotado neste trabalho: a regressão descontínua.

A ideia básica desse desenho é que unidades com valores maiores que um determinado patamar (cutoff) numa determinada variável (forcing variable) recebem tratamento, enquanto aquelas com valores menores, não. Para facilitar a compreensão, podemos operacionalizar a forcing variable como a diferença de votos entre dois candidatos numa eleição fictícia em que só há uma vaga: o candidato que obtiver uma diferença de votos positiva, isto é, o que fizer mais votos, é eleito - ou, em outras palavras, é tratado. Caso a diferença de votos entre eles seja pequena o suficiente, o perdedor pode servir como contrafactual do vencedor - o que nos permite observar a diferença entre eles ao longo do tempo, atribuída exclusivamente pelo resultado eleitoral (Imbens e Lemieux, 2008; Lee, 2008) $)^{4}$. 
No presente contexto, esse desenho compara candidatos que perderam ou venceram uma eleição por pequena margem de votos, satisfeito o pressuposto de que eles não conseguem determinar exatamente quantos votos receberão. Disso decorre que, para candidatos cujas margens de vitória e derrota são mínimas, ser eleito pode ser considerado aleatório e, portanto, os dois grupos de candidatos terão características semelhantes, como num experimento de laboratório. Pelo potencial de permitir identificar efeitos causais com dados observacionais, esse desenho vem sendo crescentemente utilizado na Ciência Política (Dunning, 2012). Mesmo sendo pouco utilizado no Brasil, o mesmo desenho já foi aplicado aqui para examinar a vantagem eleitoral dos incumbentes nos executivos municipais e, no âmbito federal, para investigar o efeito de eleger-se à Câmara sobre a probabilidade de um candidato conseguir licenças; e obter contratos governamentais para as empresas que doaram dinheiro para suas campanhas (Boas e Hidaldo, 2011; Boas et al., 2014; Magalhães, 2015; Klasnja e Titiunik, 2017).

Num sistema proporcional de lista aberta, ser eleito não depende apenas do desempenho individual de cada candidato, mas também do total de votos que as listas obtêm. Se uma coligação conquista três cadeiras, por exemplo, os três candidatos mais votados dentro dela são eleitos, mesmo que ela tenha 3 ou 30 candidatos. Por esta razão, a aplicação de regressão descontínua na Câmara precisa tomar as listas - ou coligações - como foco. Utilizando o modelo de resultados potenciais (Rubin, 1974), podemos formalizar a estratégia aplicada à Câmara da maneria a seguir (cf. Boas e Hidalgo, 2011; Boas et al., 2014).

Cada candidato que disputa as eleições obtém $x_{i j t}$ votos, em que $t$ indica a eleição, $j$ a coligação ou partido desses candidatos e $i$, além de indexar os candidatos, também indica a posição deles dentro da lista (e.g., $x_{i=1, j t}$ indica o total de votos do candidato mais bem votado da lista $j$; por definição, $x_{i=1, j t}>x_{i=2, j t}$ e assim por diante). Como parte do processo de alocação de vagas na Câmara, cada coligação $j$ numa eleição $t$ recebe $s_{j t}$ cadeiras, dependendo do total de votos obtidos pelos seus candidatos. Aqueles com $i \leq s_{j t}$ são eleitos; os com $i>s_{j t^{\prime}}$ não. Deste modo, podemos definir a margem de vitória de um candidato eleito como a diferença da votação dele em relação à do primeiro suplente (o não eleito mais bem votado da lista) e, para um candidato não eleito, como a diferença de votos deste em relação a do candidato eleito com menos votos ${ }^{5}$ : 


$$
M_{i j t}=\left\{\begin{array}{l}
x_{i j t}-x_{i=s+1, j t} \text { se } i \leq s_{j t} \\
x_{i=s, j t}-x_{i j t} \text { se } i>s_{j t}
\end{array}\right.
$$

Como apenas candidatos eleitos podem ter margens de voto positivas, as atribuições do tratamento (ser eleito) e do controle (não ser eleito) podem ser indicadas por uma variável binária, $T$, que assume o valor de 1 para candidatos com margens positivas, $M_{i j t}>0$, e 0 para candidatos derrotados, $M_{i j t}<0$. Como dito anteriormente, quanto mais próximo for $M_{i j t}$ de 0 , mais podemos assegurar que obter um mandato na Câmara foi distribuído como que aleatoriamente entre os candidatos, o que nos permite estimar o efeito do tratamento médio local (ETM), vencer, onde a margem de votos tende a 0:

$$
E T M L=\lim _{M \downarrow 0} \mathbb{E}\left[Y_{i j t}(1) \mid M_{i j t}\right]-\lim _{M \uparrow 0} \mathbb{E}\left[Y_{i j t}(0) \mid M_{i j t}\right]
$$

A intuição central desta estratégia é que, caso vencer uma eleição para a Câmara cause impacto na carreira dos candidatos eleitos, a probabilidade destes vencerem outras eleições será condicional às suas margens de votos: quando um candidato faz pelo menos um voto a mais do que o primeiro suplente, por exemplo, a probabilidade deste se eleger muda descontinuadamente de 0 para 1 e, assim, qualquer efeito do tratamento tenderá a seguir o mesmo padrão. $\mathrm{O}$ Gráfico 2 ilustra isso visualmente. Como é possível verificar, quando a margem de votos passa por 0 , representado pela linha vertical tracejada, a probabilidade de ser eleito passa de 0 a 1 , e isto provoca uma descontinuidade na variável de interesse (e.g., vantagem eleitoral), caso o tratamento cause algum efeito ${ }^{6}$. No gráfico da esquerda, a distância vertical entre as duas curvas no ponto 0 é justamente o que queremos estimar. 
Gráfico 2

Exemplo de como a regressão descontínua identifica um efeito causal
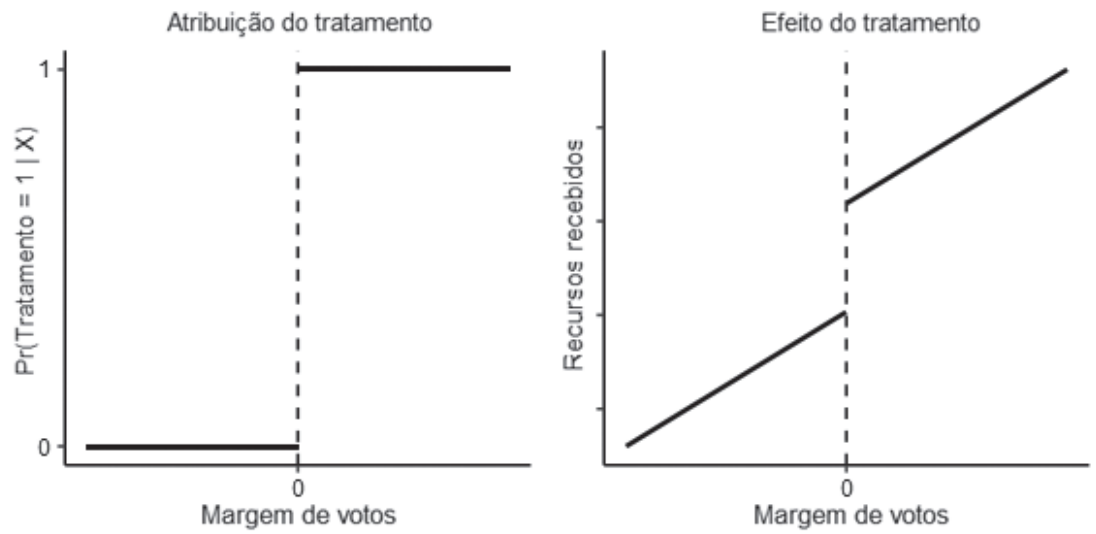

Fonte: Elaboração própria, com base em simulações computacionais.

\section{Dados}

Os dados desta análise abarcam a trajetória de todos os candidatos que já disputaram eleições para deputado federal desde 1998, compilados a partir do Repositório de Dados Eleitorais do Tribunal Superior Eleitoral (TSE). Os candidatos foram identificados ao longo do tempo por meio de uma combinação de nome completo, data de aniversário e distrito eleitoral (UF) - portanto, os raros casos de mudança de distrito entre eleições tornam-se novas observações. Para contornar erros de grafia e/ou digitação (e.g., uma candidata chamada Caroline que seja registrada como Karoline num pleito subsequente), implementei um algoritmo de fuzzy matching para ligar as ocorrências de cada candidato ao longo do tempo ${ }^{7}$. Com este banco, uma série de variáveis - votos obtidos, cargo disputado, resultado da eleição, entre outros -, foram criadas para todas as eleições anteriores e posteriores a eleição de referência, $t_{0}$. Estas informações me permitem saber, por exemplo, se os candidatos que venceram ou perderam uma eleição para a Câmara disputaram outras posteriormente, ou anteriormente.

As principais variáveis dependentes utilizadas na análise são binárias. Disputar uma eleição futura é indicado por uma dummy, em que 1 significa ter se candidatado. Quanto a vencer uma eleição, a operacionalização poderia trazer problemas de endogeneidade se fossem analisados apenas candidatos que disputaram eleições em $t_{+4}$. Por exemplo, 
podemos supor que candidatos que perdem uma eleição em $t_{0}$ para a Câmara têm menor probabilidade de concorrer novamente ao mesmo cargo; os poucos que tentam, por outro lado, poderiam ser justamente aqueles com melhores chances de vencer. Assim, restringir a análise do resultado de eleições futuras apenas aos que se candidataram novamente geraria viés de seleção amostral. Para contornar este problema, examino aqui a probabilidade incondicional de vencer uma eleição, isto é, a probabilidade de um candidato em $t_{0}$ se candidatar $e$ vencer uma eleição no futuro, e não de vencer dado que se candidatou. Como é uma condição necessária candidatar-se para vencer uma eleição, tanto estes candidatos que não disputaram a eleição em $t_{+4}$ quanto os que disputaram e perderam recebem o valor 0; os que concorreram e venceram, por sua vez, recebem o valor 1. Entre outros, esta operacionalização torna possível examinar o efeito da vitória mesmo quando muitos candidatos não disputam a reeleição, ou quando existem mais de dois candidatos, multipartidarismo e altas taxas de migração partidária (Magalhães, 2015; Klasnja e Titiunik, 2017).

A margem de voto de cada candidato, que determina a atribuição do tratamento, foi calculada de duas formas. Primeiro, por meio da diferença na porcentagem de votos dentro da lista que cada candidato fez: se o último eleito e o primeiro suplente fizerem 20\% e 10\% de todos os votos numa determinada lista, as margens deles serão 10 e -10, respectivamente. Segundo, por meio da diferença bruta de votos entre candidatos: se o último eleito de uma lista fez 100 votos e o primeiro suplente fez -50, as margens dos dois são 50 e -50 , respectivamente. Apesar de semelhantes, as duas variáveis podem captar distâncias relativamente diferentes: em distritos com mais eleitores, uma diferença de 1.000 votos entre um candidato eleito e outro não eleito pode ser traduzida numa diferença percentual mínima; assim como em distritos com menos eleitores uma diferença de 100 votos pode virar uma diferença percentual enorme. Já que na regressão descontínua a seleção de observações depende desta variável, as duas versões são utilizadas. Na próxima seção, reporto apenas os resultados da primeira variável, mas o uso da segunda não altera os resultados a seguir.

\section{Modelos}

Para estimar o efeito causal da incumbência sigo a prática convencional na literatura de estimar modelos de MQO, permitindo que o ter- 
mo linear da variável margem de votos varie à esquerda e à direita da descontinuidade (Imbens e Lemieux, 2008; Lee, 2008). Deste modo, a diferença nas duas curvas no ponto 0 é o estimador da regressão descontínua. Estes modelos seguem a seguinte forma:

$$
Y_{i j t}=\alpha+\beta T_{i j t}+\gamma M_{i j t}+\delta T_{i j t} M_{i j t}+\varepsilon_{i j t}
$$

Nesta equação, $\beta$ é o efeito causal do tratamento, e $i, j$ e $t$, como dito anteriormente, indexam os candidatos, as listas e as eleições, respectivamente. Também seguindo a prática da literatura, emprego um kernel triangular nestes modelos, o que dá maior peso às observações mais próximas da descontinuidade. Para garantir que a especificação escolhida não altere os resultados (Dunning, 2012), também estimo estes modelos de forma não paramétrica, apenas com o indicador de tratamento que compara candidatos vencedores e derrotados:

$$
Y_{i j t}=\alpha+\beta T_{i j t}+\varepsilon_{i j t}
$$

Um segundo detalhe da especificação é a seleção da janela ao redor da descontinuidade, isto é, a margem de votos que consideramos pequena o suficiente para ser considerada quase aleatória. Como estamos interessados nos candidatos que perderam ou venceram por margens mínimas, poderíamos restringir esta janela selecionando apenas candidatos cujas margens sejam quase 0 . Fazendo isto, contudo, reduziríamos consideravelmente o tamanho da amostra. $\mathrm{O}$ ideal, portanto, é selecionar uma janela que equilibre a proximidade da descontinuidade (para evitar viés no estimador) e o número de observações (para aumentar poder estatístico) (Imbens e Lemieux, 2008). O algoritmo de Imbens e Kalyanaraman (2011), que utilizo nas análises que seguem, cumprem exatamente esta função. De qualquer modo, também reporto resultados para diferenças de $1 \%$ de votos nos modelos com apenas o indicador de tratamento, além de diversas outras diferenças de votos na exibição gráfica dos resultados.

\section{Validação}

Um pressuposto central precisa ser satisfeito para que a regressão descontínua identifique o efeito causal desejado: o de que os candidatos não tenham controle exato sobre suas margens de votos ao redor da descontinuidade (Lee, 2008). Como dito acima, uma violação 
deste pressuposto significaria que alguns candidatos determinariam suas seleções para o grupo de vencedores, isto é, que haveria problema de autosseleção. Nas eleições para a Câmara, entretanto, esta hipótese é remota. Para que pudessem alterar quaisquer resultados adversos, os candidatos teriam que antecipar com muita precisão seus desempenhos nas urnas - algo difícil em diversas das democracias (Eggers et al., 2015). Este ponto é reforçado pelo fato de que as diferenças de votos entre o último eleito e o primeiro suplente dentro das listas tendem a ser relativamente pequenas. Suporte adicional também é dado pelo teste proposto por McCrary (2008), que examina a hipótese nula de que a densidade das margens de votos nos dois lados da descontinuidade é semelhante. O resultado para a amostra completa é de $\mathrm{p}=0,61$.

Outra forma de testar o desenho aqui proposto é por meio da comparação dos grupos de candidatos vencedores e derrotados. Se, como em pesquisas experimentais, a aleatoriedade na atribuição do tratamento faz com que os grupos de tratamento e controle sejam semelhantes, podemos esperar o mesmo no caso da regressão descontínua: candidatos que venceram ou perderam uma eleição por margens apertadas devem ser semelhantes, em média. Como a Tabela 1 mostra, isso acontece entre os candidatos analisados. Restringindo a amostra para incluir apenas candidatos que venceram ou perderam dentro das listas por diferenças de até $1 \%$ de votos, os dois grupos são semelhantes em diversas características, tais como ocupação profissional, sexo, estado civil, grau de instrução, patrimônio, cargos ocupados e histórico de disputas eleitorais prévias. Os resultados de testes $\mathrm{T}$ (P-valor, na última coluna), que serve para testar a hipótese nula de que não existe diferença de média entre duas amostras, corroboram este ponto ${ }^{8}$. 
Carreiras Políticas na Câmara dos Deputados: Uma Análise Quase-Experimental

Tabela 1

Balanço da amostra de candidatos a deputado federal (margem de 1\% de votos)

\begin{tabular}{lcccc}
\hline & Vencedores & Derrotados & Diferença & P-valor \\
\hline & & & & \\
Advogado & 0,12 & 0,11 & 0,01 & 0,93 \\
Empresário & 0,04 & 0,06 & $-0,02$ & 0,33 \\
Médico & 0,08 & 0,05 & 0,03 & 0,08 \\
Engenheiro & 0,04 & 0,03 & 0,01 & 0,61 \\
Servidor & 0,01 & 0,02 & $-0,01$ & 0,14 \\
Comerciante & 0,02 & 0,02 & 0 & 0,73 \\
Mulher & 0,06 & 0,08 & $-0,02$ & 0,26 \\
Ensino superior & 0,58 & 0,64 & $-0,06$ & 0,1 \\
Ensino médio & 0,09 & 0,09 & 0 & 0,79 \\
Casado & 0,65 & 0,62 & 0,03 & 0,38 \\
Bens declarados & 956896,33 & 196673,91 & 760222,42 & 0,32 \\
Gasto de campanha & 702253,75 & 576290,52 & 125963,23 & 0,31 \\
Incumbente na Câmara & 0,26 & 0,23 & 0,03 & 0,38 \\
Incumbente nas Assembleias & 0,05 & 0,05 & 0 & 0,98 \\
Disputou eleição em ${ }_{-4}$ & 0,4 & 0,45 & $-0,05$ & 0,18 \\
Disputou eleição em $t_{-2}$ & 0,17 & 0,22 & $-0,05$ & 0,05 \\
\hline Fonte: Elaboração própria com base em dados do TSE. & &
\end{tabular}

Fonte: Elaboração própria com base em dados do TSE.

\section{Resultados}

O Gráfico 3 mostra os principais resultados deste artigo: incumbentes têm probabilidades muito maiores de se candidatarem e de vencerem a eleição seguinte do que os candidatos derrotados no $t_{0}$. Nos gráficos à esquerda a variável margem de votos no eixo $X$ foi dividida em intervalos de $1 \%$ (representados pelos pontos pretos), que indicam a probabilidade dos candidatos com votos situadas nestes intervalos de concorrer e/ou ocupar o mesmo cargo quatro anos depois. Nos dois casos, é possível visualizar uma distância expressiva entre as duas curvas quando a margem de votos toca o ponto 0 , indicando que vencer uma eleição para a Câmara dos Deputados aumenta substantivamente a probabilidade de um candidato concorrer e vencer a reeleição. 
Gráfico 3

Efeito causal de vencer em $t 0$ sobre a probabilidade de concorrer $e$ de concorrer e vencer em $t_{+4}$
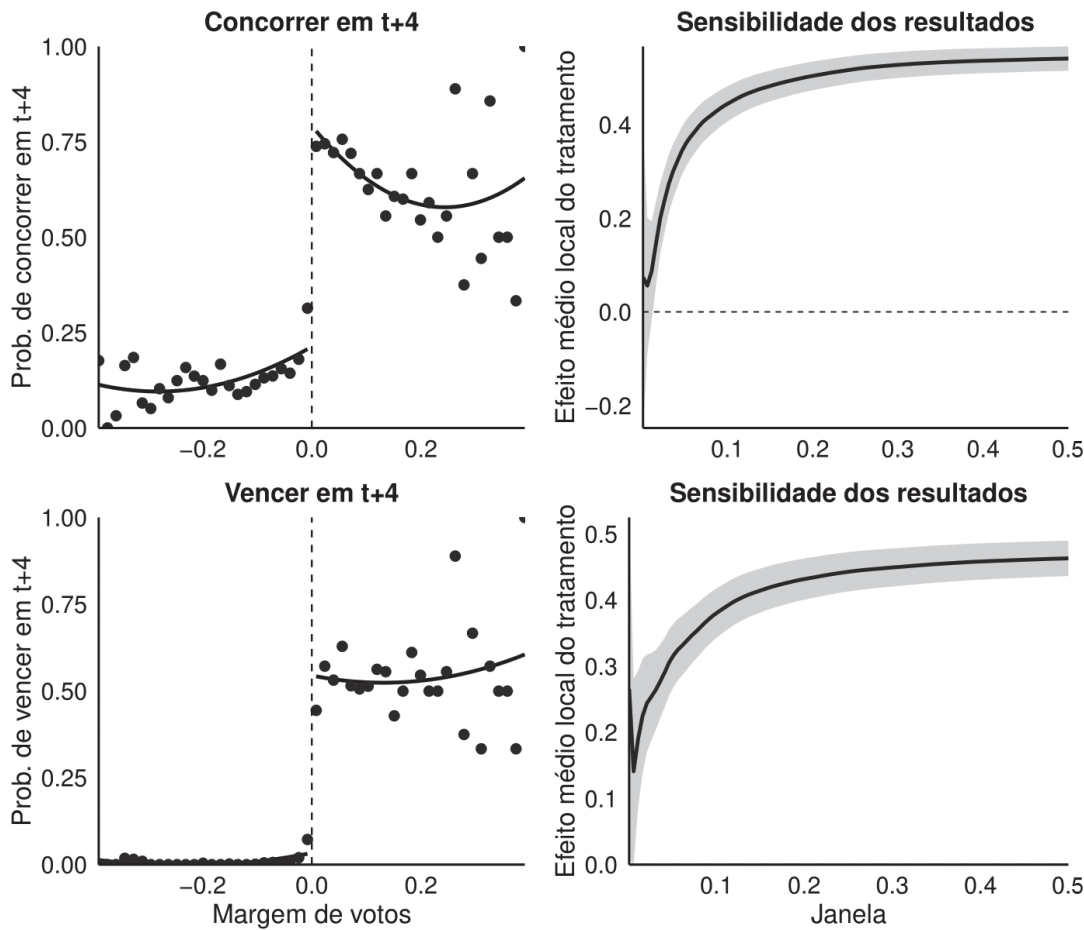

Fonte: Elaboração própria com base em dados do TSE.

Nota: Os gráficos à esquerda mostram o salto nas variáveis dependentes na descontinuidade. $\mathrm{O}$ eixo $\mathrm{X}$ é a diferença na proporção de votos dentro das listas eleitorais dos candidatos vencedores (perdedores) em relação ao primeiro não eleito (último eleito). As curvas foram estimadas com polinômio de ordem 2 nos dois lados da descontinuidade. Os pontos são a média das observações de $Y$ em intervalos de 0,01 da margem de vitória. Os gráficos à direita mostram os efeitos do tratamento em diferentes janelas ao redor da descontinuidade (quantas observações ao redor de 0 são incluídas no modelo). A linha horizontal tracejada identifica o local em que o efeito é 0. 
Tabela 2

Efeito causal de vencer eleição para a Câmara dos Deputados sobre a probabilidade de disputar e obter o mesmo cargo no futuro

\begin{tabular}{lcccc}
\hline \multicolumn{1}{c}{ Variável dependente } & Estimativa & Erro-padrão & Margem (\%) & $\mathrm{N}$ \\
\hline Concorrer em $t_{+4}($ linear $)$ & $0,11^{*}$ & 0,05 & 1,33 & 1852 \\
Concorrer em $t_{+4}$ & $0,28^{*}$ & 0,03 & 1 & 1455 \\
Vencer em $t_{+4}($ linear $)$ & $0,24^{*}$ & 0,04 & 1,99 & 2861 \\
Vencer em $t_{+4}$ & $0,29^{*}$ & 0,03 & 1 & 1455 \\
Vencer em $t_{+8}($ linear $)$ & $0,13^{*}$ & 0,04 & 1,99 & 2266 \\
Vencer em $t_{+8}$ & $0,17^{*}$ & 0,03 & 1 & 1205 \\
Vencer em $t_{+12}$ (linear) & $0,09^{*}$ & 0,04 & 2,02 & 1806 \\
Vencer em $t_{+12}$ & $0,12^{*}$ & 0,03 & 1 & 942 \\
\hline
\end{tabular}

Fonte: Elaboração própria com base em dados do TSE.

Nota: * p-valor $<0.05$. Erros-padrão robustos entre parênteses. As estimativas mostram o efeito causal de ser incumbente na Câmara sobre as variáveis dependentes indicadas. Linear, entre parênteses, indica os modelos que foram estimados com a inclusão de um termo linear para a margem de votos nos modelos.

Conforme pode ser visto mais detalhadamente na Tabela 2, entre os candidatos a deputado federal com diferenças pequenas de votos dentro das listas, os vitoriosos se candidatam mais ao mesmo cargo que os derrotados quatro anos depois. O mais expressivo, contudo, é o sucesso na busca da reeleição que os incumbentes desfrutam: têm probabilidade 0.24 , i.e. 24 pontos percentuais a mais de vencer quatro anos depois. As colunas da tabela mostram também que, apesar de variações, os resultados se mantêm inalterados quando são utilizadas diferentes margens de votos (a coluna margem indica a margem percentual de votos utilizada) e especificações (os modelos com termos lineares para a margem de votos são indicados por linear, entre parênteses) para estimar o efeito do tratamento. De forma semelhante, a margem de votos utilizada para selecionar os candidatos não altera substancialmente estes resultados, como mostram a coluna à direita no Gráfico 3. No eixo X é indicada a margem de votos utilizada (janela), e no eixo Y o efeito causal estimado, acompanhado de intervalos de confiança de $95 \%$.

Mas estes resultados contam apenas parte da história. O efeito de vencer uma eleição para a Câmara permanece mesmo depois de oito ou doze anos. Como mostra o Gráfico 4, ainda é nítido o salto entre as duas curvas ao redor da descontinuidade, indicando efeito ainda expressivo. Em média, um candidato que quase venceu uma eleição para a Câmara ainda tem probabilidade de cerca de 15 pontos percentuais a mais de vencer oito anos depois, e de cerca de 10 pontos doze anos depois. Pelo tamanho 
reduzido da série temporal dos dados, não é possível investigar o mesmo efeito 16 anos depois. Dos candidatos a deputado federal em 2010, por exemplo, só é possível examinar seus resultados na eleição subsequente; dos candidatos em 2006, seus resultados até duas eleições depois. Retrocedendo um pouco mais, contudo, o número de observações diminui consideravelmente. No caso de três eleições (doze anos depois), o número de observações cai para 942, mas isto não afeta os resultados: como mostra o Gráfico 4, independentemente da janela utilizada, o efeito permanece positivo. Vencer uma eleição apertada para a Câmara, portanto, causa uma mudança expressiva nas carreiras dos candidatos que venceram por margens pequenas, alterando seus tipos de ambição e chances de sucesso tanto no curto quanto no longo prazo.

\section{Gráfico 4}

Efeito causal de vencer em $t_{0}$ sobre a probabilidade de concorrer $e$ de concorrer e vencer em $\mathbf{t}_{+8}$ e em $\mathbf{t}_{+12}$
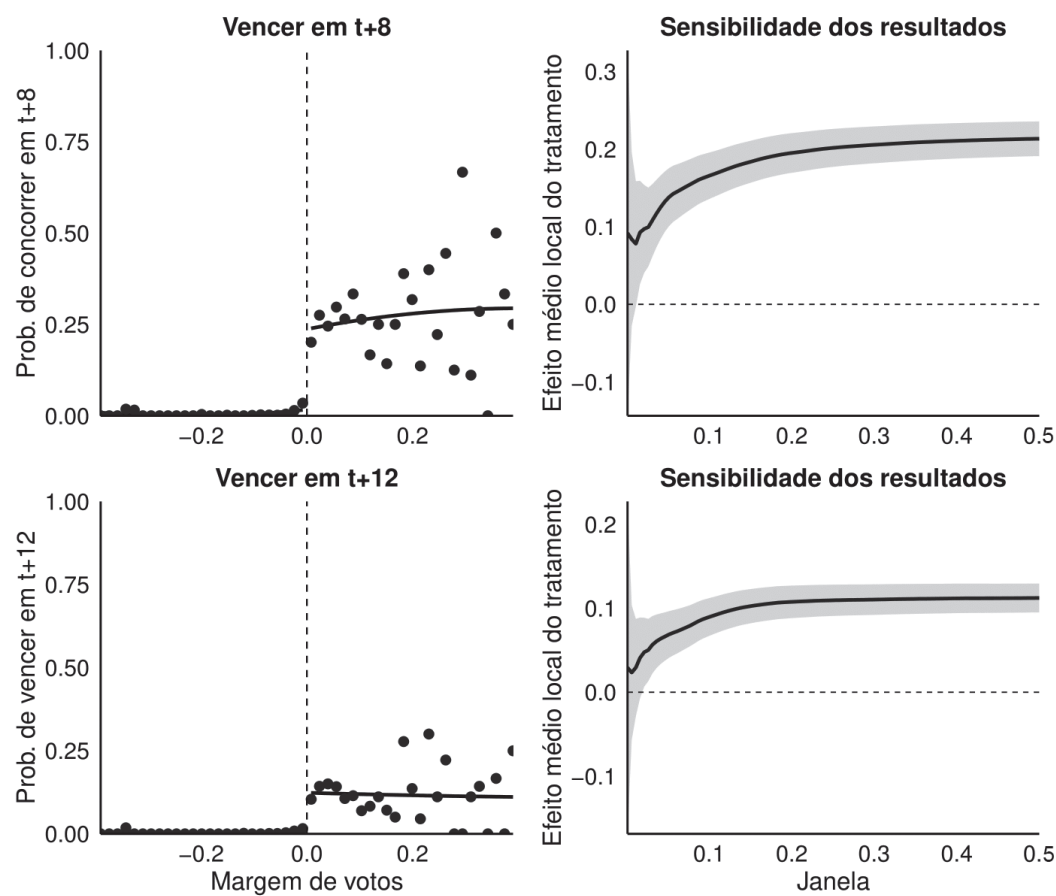

Fonte: Elaboração própria com base em dados do TSE.

Nota: Os gráficos à esquerda mostram o salto nas variáveis dependentes na descontinuidade. o eixo $\mathrm{X}$ é a diferença na proporção de votos dentro das listas eleitorais dos candidatos vencedores (perdedores) em relação ao primeiro não eleito (último eleito). As curvas foram estimadas com polinômio de ordem 2 nos dois lados da descontinuidade. Os pontos são a média das observações de Y em intervalos de 0,01 da margem de vitória. Os gráficos à direita mostram os efeitos do tratamento em diferentes janelas ao redor da descontinuidade (quantas observações ao redor de 0 são incluídas no modelo). A linha horizontal tracejada identifica o local em que o efeito é 0. 
Cabe notar, contudo, que esses resultados nada dizem sobre o desempenho dos incumbentes em relação a candidatos estreantes, aqueles que disputam eleições em $t_{+4}$ mas não em $t_{0}$. Ao comparar candidatos que quase perderam com os que quase venceram, é possível estimar apenas o efeito causal da incumbência sobre a carreira futura de um candidato - o que não é o mesmo que afirmar que incumbentes têm benefícios eleitorais na busca da reeleição num sentido amplo. Se é verdade que incumbentes geralmente fazem mais votos que candidatos desafiantes (Perissinotto e Miríade, 2009), parte da explicação pode estar sendo captada pelos resultados acima - já que é plausível supor que os benefícios de obter um cargo na Câmara incentivam os incumbentes a tentar e a ter sucesso na reeleição. De todo modo, essa não é a questão central deste artigo. Feitas essas ponderações, os resultados reportados indicam que vencer uma eleição apertada para a Câmara faz diferença considerável na carreira de um candidato.

\section{Efeitos nas disputas por outros cargos}

Como a seção anterior procurou mostrar, obter um mandato na Câmara incentiva o candidato a buscar a reeleição, ao contrário do que ocorre com um candidato derrotado. Mas e quanto a outros cargos, como o de prefeito e senador? Os vitoriosos também têm maiores chances de obtê-los no futuro? E o que acontece com as carreiras políticas dos candidatos derrotados? Passo a examinar estas questões a seguir para mapear mais detidamente os caminhos de carreira dos candidatos nas eleições para deputado federal. Para isto, emprego o mesmo desenho de pesquisa utilizado anteriormente, alterando apenas as variáveis dependentes. Especificamente, examino uma série de dummies que indicam se um candidato numa determinada eleição para a Câmara disputou, e disputou $e$ obteve, outros cargos (vereador e/ou prefeito, deputado estadual, senador, governador e/ou vice-governador); ou se aposentou (não disputou cargos eletivos 12 anos subsequentes).

Como pode ser visto na primeira imagem do Gráfico 5, quando a margem de votos de um candidato passa pela descontinuidade - significando que obteve um mandato de deputado federal - sua probabilidade de concorrer nas eleições municipais dois anos depois, seja para o cargo de prefeito ou de vereador (Concorrer em $t_{+2}$ ), cai visivelmente. Em outras palavras, este resultado mostra que candidatos que perdem uma eleição apertada para a Câmara são mais propensos 
a disputar algum cargo no nível municipal, o que pode ser interpretado como uma tentativa de sobrevivência política no curto prazo. Apesar disso, as chances destes candidatos vencerem nessas eleições locais vis-à-vis candidatos que venceram em $t_{0}$ são praticamente inexistentes: as duas curvas ao redor da descontinuidade quase se tocam, embora ainda indique que os candidatos derrotados nas eleições para a Câmara em $t_{0}$ levam alguma vantagem. Segundo os resultados da Tabela 3, contudo, podemos ver que esta pequena vantagem não é estatisticamente significativa - o coeficiente para esta variável no modelo linear (Vencer no executivo $t_{+2}$ ) é de $-0,01$, indicando que os derrotados têm probabilidade de 1 ponto a mais que os vencedores de obter algum cargo nas eleições municipais dois anos depois, mas apresenta erro-padrão de 0,02. De acordo com este resultado, não parece ser nem o caso de que ocupar um cargo legislativo sirva necessariamente como um trampolim para se obter um cargo de prefeito; e nem de que prefeituras sejam prêmios de consolação para os derrotados em $t_{0}$. 
Gráfico 5

Efeito causal de vencer em $t_{0}$ sobre a probabilidade de concorrer $e$ de concorrer e vencer em $t_{+2}$ e de se aposentar
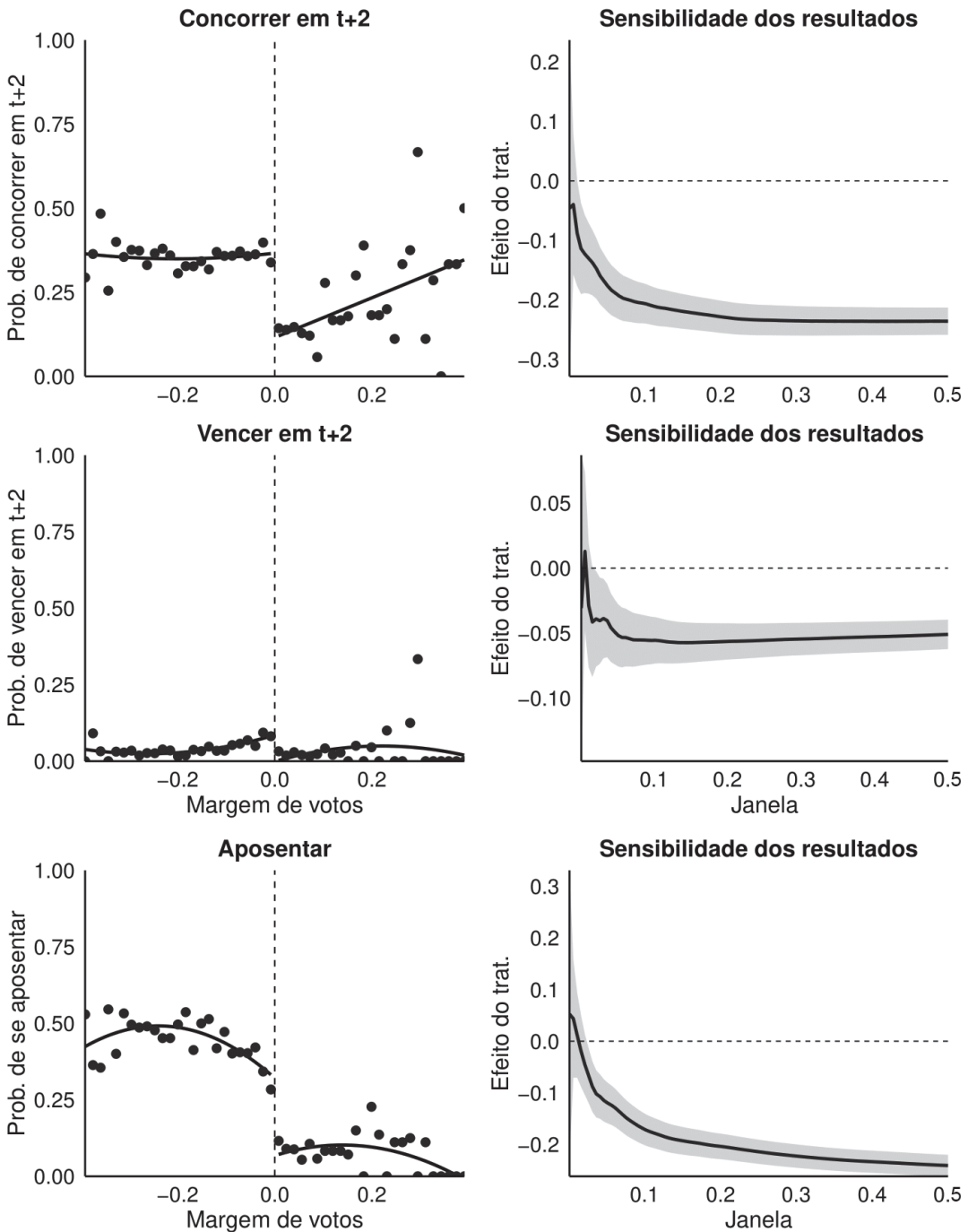

Fonte: Elaboração própria com base em dados do TSE.

Nota: Os gráficos à esquerda mostram o salto nas variáveis dependentes na descontinuidade. $\mathrm{O}$ eixo $\mathrm{X}$ é a diferença na proporção de votos dentro das listas eleitorais dos candidatos vencedores (perdedores) em relação ao primeiro não eleito (último eleito). As curvas foram estimadas com polinômio de ordem 2 nos dois lados da descontinuidade. Os pontos são a média das observações de Y em intervalos de 0,01 da margem de vitória. Os gráficos à direita mostram os efeitos do tratamento em diferentes janelas ao redor da descontinuidade (quantas observações ao redor de 0 são incluídas no modelo). A linha horizontal tracejada identifica o local em que o efeito é 0. 
Tabela 3

Efeito causal de vencer eleição na Câmara sobre a probabilidade de disputar e obter o mesmo cargo no futuro

\begin{tabular}{|c|c|c|c|c|}
\hline Variável dependente & Estimativa & $\begin{array}{c}\text { Erro- } \\
\text { padrão }\end{array}$ & $\begin{array}{c}\text { Margem } \\
(\%)\end{array}$ & $\mathrm{N}$ \\
\hline Concorrer em $t_{+2}($ linear $)$ & $-0,11^{*}$ & 0,04 & 1,69 & 2345 \\
\hline Concorrer em $t_{+2}^{+2}$ & $-0,15^{*}$ & 0,03 & 1 & 1455 \\
\hline Concorrer a dep. estadual $t_{+4}$ (linear) & $-0,06^{*}$ & 0,02 & 1,98 & 2842 \\
\hline Concorrer a dep. estadual $t_{+4}^{+4}$ & $-0,07^{*}$ & 0,01 & 1 & 1455 \\
\hline Vencer em $t_{+2}($ linear $)$ & $-0,04$ & 0,02 & 1,61 & 2239 \\
\hline Vencer em $t_{+2}^{+2}$ & $-0,05^{*}$ & 0,01 & 1 & 1455 \\
\hline Vencer prefeito em $t_{+2}$ (linear) & $-0,01$ & 0,02 & 1,53 & 2113 \\
\hline Vencer prefeito em $t_{+2}^{+2}$ & $-0,01$ & 0,01 & 1 & 1455 \\
\hline Vencer vereador em $t_{+2}^{+2}$ (linear) & $-0,03^{*}$ & 0,01 & 1,5 & 2069 \\
\hline Vencer vereador em $t_{+2}^{+2}$ & $-0,04^{*}$ & 0,01 & 1 & 1455 \\
\hline Vencer dep. estadual $t_{+4}^{+2}$ (linear) & $-0,02$ & 0,01 & 1,18 & 1667 \\
\hline Vencer dep. estadual $t_{+4}^{+4}$ & $-0,01$ & 0,01 & 1 & 1455 \\
\hline Eleger-se governador ou senador em $t_{+4}$ (linear) & $-0,01$ & 0,01 & 1,01 & 1470 \\
\hline Eleger-se governador ou senador em $t_{+4}$ & 0 & 0 & 1 & 1455 \\
\hline Aposentar-se (linear) & $-0,03$ & 0,03 & 1,79 & 2490 \\
\hline Aposentar-se & $-0,09^{*}$ & 0,02 & 1 & 1455 \\
\hline
\end{tabular}

Fonte: Elaboração própria com base em dados do TSE.

Nota: ${ }^{*}$ p-valor $<0,05$. Erros-padrão robustos entre parênteses. As estimativas mostram o efeito causal de ser incumbente na Câmara sobre as variáveis dependentes indicadas. Linear, entre parênteses, indica os modelos que foram estimados com a inclusão de um termo linear para a margem de votos nos modelos.

Em conjunto com os resultados apresentados na seção anterior, temos um quadro mais acurado do efeito das eleições para a Câmara dos Deputados sobre as carreiras dos políticos brasileiros. Pelo que foi apresentado até aqui, fica claro que os candidatos que obtêm um mandato passam a priorizar as eleições para o mesmo cargo no futuro, enquanto que os derrotados abdicam dessa ambição para disputar cargos eletivos municipais - ainda que a maior parte deles não seja bem-sucedida. O que é mais interessante é que para outro grupo de candidatos a derrota por poucos votos na Câmara pode significar uma espécie de aposentadoria. A última imagem à esquerda do Gráfico 5 ilustra este efeito: a probabilidade de um candidato se aposentar, isto é, de não disputar nenhum cargo eletivo pelos próximos 12 anos depois da derrota na eleição em $t_{0}$, é muito maior para os candidatos derrotados (segundo a Tabela 3, entre 0,03 e 0,09, ou 3 e 9 pontos percentuais a mais). Neste sentido, mesmo uma mínima diferença de votos, como visto, pode causar um efeito grande em suas carreiras políticas futuras: no primeiro caso, significando maior probabilidade 
de disputar e ser eleito ao mesmo cargo (deputado); já no segundo, implicando em perda de ambições progressivas e, além disso, maiores chances de não candidatar-se mais.

Quanto aos demais cargos disponíveis no sistema político brasileiro, os resultados seguem padrão similar ao do quadro esboçado acima. De acordo com os modelos estimados na Tabela 3, candidatos derrotados nas eleições para a Câmara têm probabilidade de cerca de 0,06 a mais de concorrer ao cargo de deputado estadual quatro anos depois. Como este cargo geralmente é mais fácil de ser obtido, visto que o número de vagas é maior, isto pode ser visto como uma tentativa racional de adequar a ambição de carreira com o desempenho eleitoral passado: candidatos derrotados por poucos votos podem calcular que se tivessem disputado uma vaga nas assembleias estaduais teriam sido eleitos. $\mathrm{O}$ que acontece quatro anos depois, entretanto, tende a frustrar esta estratégia: a probabilidade de um candidato derrotado para a Câmara em $t_{0}$ obter um cargo de deputado estadual em $t_{+4}$ é de, no máximo, 2 pontos percentuais a mais em comparação aos candidatos vencedores em $t_{0}$. Todavia, esse efeito não é signi cativamente diferente de 0 . Ao desagregar as eleições municipais por cargo, é possível perceber que a única disputa em que os derrotados em $t_{0}$ se saem melhor é para o cargo de vereador, em que estes têm probabilidade de 0,04 a mais de vencer.

A Tabela 3 ainda mostra outros efeitos do tratamento. Particularmente, obter ou não um mandato de deputado federal por poucos votos não parece causar qualquer efeito sobre as chances futuras de um candidato de vencer os cargos de senador (mesmo como suplentes da chapa) ou de governador e vice-governador. Para estes, talvez passar pela Câmara não seja suficiente para incentivá-los a ambicionar voos mais altos, especialmente quando se considera a necessidade de captar votos em maiores áreas de um distrito, obter mais recursos de campanha, e coordenar esforços com outros partidos por meio de coligações, para almejar chances reais de vitória. O mesmo, porém, também ocorre nas eleições para prefeito dois anos depois: o resultado da eleição em $t_{0}$ não afeta suas probabilidades de se candidatar e de vencer a eleição para prefeito.

Em resumo, candidatos que perdem uma eleição apertada para a Câmara tendem a optar por três grandes caminhos: disputar o cargo de vereador dois anos depois com chances de vencer; disputar o cargo 
de deputado estadual quatro anos depois, com chances mínimas de vencer; ou deixar de disputar novos cargos eletivos (ao menos pelos próximos 12 anos). Desse modo, pode-se sustentar que a influência da Câmara na carreira de um político importa, afetando de maneira inversa a candidatos vencedores e derrotados, apenas em decorrência da ocupação do cargo. Por um lado, ela alavanca os desempenhos futuros dos candidatos que se tornam deputados federais, dando a eles maiores chances de permanecer na política nacional por longos períodos. Por outro lado, tem efeito centrífugo sobre as carreiras dos candidatos que tentam integrá-la sem sucesso, incentivando-os sobretudo a ocupar cargos nos legislativos municipais, ou a desistir de concorrer a outros cargos.

\section{Resultados adicionais}

Conforme discutido neste artigo, existem outros fatores, além da ocupação de vaga na Câmara, que podem influir na carreira futura de um político - como a competição eleitoral em seu distrito. Embora não seja possível identificar o efeito causal deles sobre a carreira dos candidatos usando o mesmo desenho empregado até agora, podemos avançar na interpretação dos achados investigando o efeito marginal do tratamento em relação a algumas dessas variáveis. Para isso, uso nos modelos um termo multiplicativo entre elas e o indicador de tratamento ${ }^{9}$. Novamente, cabe a ressalva de que isso equivale a investigar, de forma correlacional, como o efeito estimado varia entre subgrupos de candidatos.

O Gráfico 6 exibe os resultados desses testes nas variáveis "magnitude eleitoral do distrito" e "status dos candidatos"(dummy que assume valor de 1 quando estes são incumbentes). Como é possível observar, quanto maior o número de cadeiras em disputa num estado para a Câmara, maior é o efeito causal de eleger-se sobre a probabilidade de disputar a reeleição. Esse achado é consistente com a ideia de que incumbentes que enfrentam menor competição eleitoral têm maiores incentivos para tentarem a reeleição que os candidatos derrotados. Por outro lado, incumbentes que se reelegem por poucos votos têm probabilidade levemente inferior de tentar a reeleição se comparados aos candidatos não incumbentes vencedores. Mas, como indicam os intervalos de confiança, essa diferença não é significativa. 
Gráfico 6

Efeito marginal do tratamento em relação à magnitude eleitoral e status dos candidatos

Magnitude do distrito

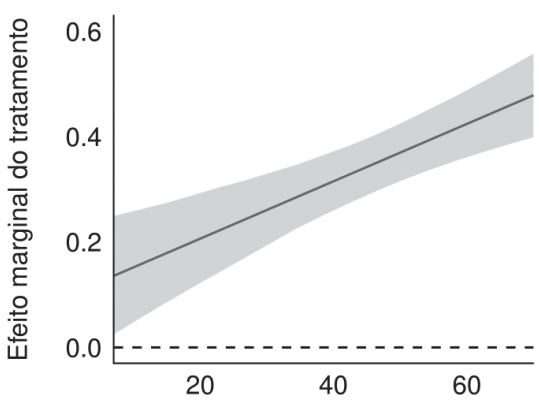

Status do candidato

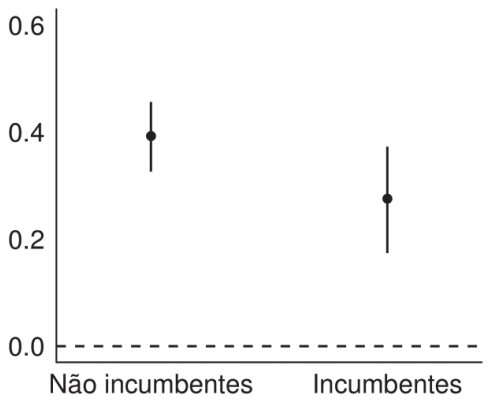

Fonte: Elaboração própria com base em dados do TSE.

Nota: Os gráficos reportam o efeito marginal do tratamento em valores das variáveis indicadas no eixo $X$. As estimativas foram feitas usando a especificação do modelo com indicador binário de tratamento, com candidatos vencedores e derrotados por menos de $1 \%$ da margem de votos.

\section{Robustez dos resultados}

Para dar maiores garantias de que os resultados reportados não são sensíveis à operacionalização do desenho da pesquisa, alguns testes adicionais foram feitos. Primeiro, utilizando polinômios nos modelos lineares (i.e., elevando margem de votos ao quadrado e ao cubo), os resultados não se alteram. Segundo, conforme dito anteriormente, usar as margens brutas de votos em vez das margens percentuais também não altera substancialmente os resultados. Terceiro, como existem mais candidatos derrotados do que vencedores na amostra, também empreguei outra amostra com apenas o último vencedor e o primeiro suplente de cada lista; novamente, embora o $\mathrm{N}$ diminua sensivelmente (para pouco mais de 400 candidatos), os principais resultados se mantêm. Por fim, cabe destacar que, pela natureza dos dados usados aqui, não foi possível identificar se um candidato eleito saiu no meio do mandato, ou se um derrotado veio a assumir um posto. De qualquer forma, estas ocorrências não invalidam os resultados, já que apenas tornam mais difícil corroborar a hipótese alternativa de que derrotados e vencedores têm carreiras futuras, em média, diferentes. Dito de outro modo, esta limitação trabalha no sentido contrário das hipóteses alternativas testadas. 


\section{CONCLUSÃO}

O objetivo deste artigo foi examinar como a obtenção de um mandato na Câmara dos Deputados afeta a carreira de um político. O resultado mais geral mostrou que, conforme sustentam alguns estudos, este cargo é importante na formação de padrões de carreiras no Brasil: entre candidatos que ficaram muito próximos de vencer ou perder uma vaga para a Câmara, os vencedores têm probabilidades maiores de concorrer à reeleição e de serem bem-sucedidos. Além disso, esse efeito se mantém por até 12 anos, mostrando que eles têm maior facilidade de desenvolver carreiras longas do que os candidatos derrotados. Portanto, os efeitos do sistema eleitoral e os baixos incentivos que os deputados teriam para permanecer na Câmara, que lhes proporcionariam pouco poder de influência sobre o policy-making, não são suficientes para anular o impacto independente das eleições sobre as carreiras dos candidatos a deputado federal.

Outro achado deste estudo é que os candidatos que não foram eleitos numa determinada eleição para a Câmara dos Deputados priorizam eleições municipais dois anos depois, talvez como tentativa de sobreviver politicamente. Desse modo, os dois grupos de candidatos, vencedores e derrotados, seguem trajetórias diferentes dependendo da distribuição do tratamento: estes últimos são menos propensos a ambicionar o nível federal, enquanto os incumbentes buscam preferencialmente se manter na Câmara. Em suma, os resultados colaboram com a literatura sobre carreiras legislativas ao mostrar que (1) vencer uma eleição para a Câmara incentiva políticos para permanecer no mesmo posto, independentemente de outros fatores; e (2) que este efeito dura por longo período, o que tende a contribuir para a diminuição da renovação parlamentar.

De qualquer modo, estes resultados têm limites de generalização. Para garantir a validade interna, a regressão descontínua põe ênfase nas observações mais próximas da descontinuidade, isto é, naqueles candidatos que perderam ou venceram por pequenas margens de votos dentro das listas eleitorais - o que é o mesmo que dizer que o efeito causal de vencer é identificado apenas para estes candidatos. Do mesmo modo, como a seleção dos grupos de tratamento e controle é feita pelo resultado eleitoral, e não pelo status de ser incumbente ou desafiante, os resultados contribuem apenas indiretamente a esse debate: especificamente, ao mostrar que a ocupação de um cargo possui 
valor intrínseco em termos de carreira, sugerindo que o mesmo pode se estender para qualquer candidato.

Feitas essas ressalvas, a investigação realizada é útil em diversos sentidos. Primeiro, porque se mesmo os candidatos que venceram por poucos votos têm maiores chances de permanecer na Câmara por até 12 anos, é razoável supor que candidatos que venceram por mais votos tenham no mínimo as mesmas chances, ou que, inclusive, passem a ambicionar cargos mais importantes, como o de senador. Segundo, os contrafactuais destes candidatos vencedores são os derrotados com melhores desempenhos, o que descarta a possibilidade de que se estivessem comparando candidatos eleitos com outros que foram recrutados apenas para compor nominata ou carrear votos para a lista.. Ademais, como demonstrado, candidatos vencedores e derrotados por poucos votos são bons grupos de tratamento e controle, já que possuem, em média, características semelhantes. Dito isto, os resultados apresentados fornecem contribuição empírica sólida para a literatura sobre carreiras políticas no Brasil.

Este artigo também abre caminho para investigações futuras. Como procurei mostrar, uma única eleição para a Câmara pode alterar substancialmente a carreira de milhares de candidatos, alçando uns à política nacional, mas restringindo outros ao limite do âmbito local. Mas é possível avançar ainda mais nestas questões. Em particular, também é possível investigar se a obtenção de outros cargos, como o de vereador, prefeito, deputado estadual e senador, causam efeitos semelhantes na carreira de um político, o que permitiria construir um panorama detalhado dos incentivos de carreira e tipo de ambição que cada cargo eletivo no sistema político brasileiro gera aos seus ocupantes.

Também é possível investigar a heterogeneidade deste efeito, isto é, se ele afeta distintamente indivíduos diferentes. Este pode ser o caso de carreiras em diferentes estados, que podem apresentar padrões de competição diferentes e, por consequência, gerar padrões de carreiras também diferentes. Como procurei mostrar por meio de um exercício simples, a magnitude de um distrito tem relação com esse efeito. Também pode ser o caso de partidos ou famílias ideológicas, já que, como sustentam Marenco e Serna (2007), candidatos a deputado nacional são recrutados de formas distintas na esquerda e na direita. De forma similar, características anteriores dos candidatos, como cargos ocupados fora do le- 
gislativo, número de mandatos eletivos exercidos, ou ainda sua posição em relação às coalizões de governo estadual e federal, podem fornecer recursos para incumbentes disputarem outros cargos (Borges e Sanchez Filho, 2016). Partindo do desenho de pesquisa adotado, estas e outras hipóteses podem ser testadas, gerando acúmulo de conhecimento mais robusto sobre os padrões de carreiras políticas no Brasil, e ajudando a compreender os incentivos e constrangimentos produzidos pela estrutura de oportunidades do sistema político nacional.

(Recebido para publicação em 24 de setembro de 2016)

(Reapresentado em 6 de abril de 2018)

(Aprovado para publicação em 20 de dezembro de 2018)

\section{NOTAS}

1. Na verdade, isto ocorreu até 2015, antes da aprovação da Proposta de Emenda à Constituição (PEC) 86, que tornou obrigatória a execução das emendas individuais até um limite de 1,2\% da Receita Líquida Corrente, 50\% delas alocadas necessariamente na saúde.

2 Ver também Pereira e Rennó (2013).

3. Estas simulações e as demais análises deste artigo foram feitas no ambiente de programação R (3.3.1).

4. Outros estudos adotam o pressuposto mais flexível de que os resultados potenciais são continuamente relacionados com a forcing variable. De qualquer forma, este também se aplica ao desenho aqui proposto.

5. Na amostra, não existe nenhum caso em que a votação do último eleito e a do primeiro suplente sejam iguais.

6. Este desenho, chamado na literatura de sharp, se aplica aos casos em que a atribuição do tratamento é uma função determinística da forcing variable. Para outros desenhos, ver Imbens e Lemieux (2008).

7. O procedimento foi feito com o pacote fuzzyjoin do ambiente de programação R. De qualquer forma, casos com erros de grafia constituem menos de $2 \%$ da amostra, e a sua exclusão não altera os resultados reportados.

8. Para testar o balanço da amostra, Imbens e Lemieux (2008) sugerem utilizar estas variáveis pré-tratamento como dependentes em regressões descontínuas. Estes testes, não reportados por economia de espaço, corroboram a Tabela 1 . O uso de testes de Qui-quadrado nas variáveis binárias também não altera estes resultados.

9. Agradeço a um(a) parecerista anônimo(a) a sugestão para realizar estes testes. Outra possibilidade seria investigar se a eleição afeta os incentivos para mudar de partido, mas esse resultado não é observado para candidatos que não disputaram nenhum cargo eletivo no futuro. Imputando o valor de 0 a esses casos (supondo que quem não se candidata não muda de partido), a estimativa é de que eleger-se aumenta a probabilidade de migrar de partido em cerca de 0,07 pontos percentuais, p-valor < 0,001. 


\section{REFERÊNCIAS BIBLIOGRÁFICAS}

AMES, Barry. (1995), "Electoral strategy under open-list proportional representation". American Journal of Political Science, v. 39, n. 2, pp. 406-433.

ANSOLABEHERE, Stephen; SNYDER Jr., James; STEWART III, Charles. (2000), “Old voters, new voters, and the personal vote: Using redistricting to measure the incumbency advantage". American Journal of Political Science, v. 44, n. 1, pp. 17-34.

BOAS, Taylor; HIDALGO, Daniel; RICHARDSON, Neal. (2014), “The spoils of victory: Campaign donations and government contracts in Brazil". The Journal of Politics, v. 76, n. 2, pp. $415-429$.

BOAS, Taylor; HIDALGO, Daniel. (2011), "Controlling the airwaves: Incumbency advantage and community radio in Brazil". American Journal of Political Science, v. 55, n. 4, pp. 869-885.

BORCHERT, Jens. (2011), "Individual ambition and institutional opportunity: A conceptual approach to political careers in multi-level systems". Regional and Federal Studies, v. 21, n. 2, pp. 117-140.

BORGES, André; SANCHEZ FILHO, Alvino. (2016), "Federalismo, coalizões de governo e escolhas de carreira dos Deputados Federais". Opinião Pública, v. 22, n. 1, pp. 1-27.

BORGES, André; PAULA, Carolina; SILVA, Adriano. (2016), "Eleições legislativas e geografia do voto em contexto de preponderância do Executivo". Revista de Sociologia e Política, v. 24, n. 58, pp. 31-58.

DUNNING, Thad. (2012), Natural experiments in the social sciences: A design-based approach. Cambridge: Cambridge University Press.

EGGERS, Andrew et al. (2015), "On the validity of the regression discontinuity design for estimating electoral effects: New evidence from over 40,000 close races". American Journal of Political Science, v. 59, n. 1, pp. 259-274.

EPSTEIN, David et al. (1997), "A comparative approach to legislative organization: Careerism and seniority in the United States and Japan". American Journal of Political Science, v. 41, n. 3, pp. $965-998$.

ERIKSON, Robert. (1971), "The advantage of incumbency in congressional elections". Polity, v. 3, n. 3, pp. 395-405.

FOWLER, Anthony; HALL, Andrew. (2017), "Long-term consequences of election results". British Journal of Political Science, v. 47, n. 2, pp. 351-372.

GELMAN, Andrew; KING, Gary. (1990), "Estimating incumbency advantage without bias". American Journal of Political Science, v. 34, n. 4, pp. 1142-1164.

GRAÇA, Luís Felipe; SOUZA, Cíntia. (2014), “Uso estratégico de eleições alternadas? Efeitos da candidature para prefeito sobre a votação dos concorrentes ao cargo de deputado federal no Brasil". Opinião Pública, v. 20, n. 3, pp. 326-345.

IMBENS, Guido; KALYANARAMAN, Karthik. (2011), “Optimal bandwidth choice for the regression discontinuity estimator". The Review of Economic Studies, v. 79, n. 3, pp. 933-959. 


\section{Fernando Meireles}

IMBENS, Guido; LEMIEUX, Thomas. (2008), "Regression discontinuity designs: A guide to practice". Journal of econometrics, v. 142, n. 2, pp. 615-635.

KLASNJA, Marko; TITIUNIK, Rocío. (2017), “The incumbency curse: Weak parties, term limits, and unfulfilled accountability". American Political Science Review, v. 111, n. 1, pp. 129-148.

LEE, David. (2008), "Randomized experiments from non-random selection in US House elections". Journal of Econometrics, v. 142, n. 2, pp. 675-697.

LEMOS, Leany; MARCELINO, Daniel; PEDERIVA, João. (2010), "Porque dinheiro importa: a dinâmica das contribuições eleitorais para o Congresso Nacional em 2002 e 2006". Opinião Pública, v. 16, n. 2, pp. 366-393.

LEONI, Eduardo; PEREIRA, Carlos; RENNÓ, Lúcio. (2003), “Estratégias para sobreviver politicamente: escolhas de carreiras na Câmara de Deputados do Brasil". Opinião Pública, v. 9, n. 1, pp. 44-67.

MAGALHÃES, Leandro. (2015), "Incumbency effects in a comparative perspective: Evidence from Brazilian mayoral elections". Political Analysis, v. 23, n. 1, pp. 113-126.

MARENCO, André; SERNA, Miguel. (2007), "Por que carreiras políticas na esquerda e na direita não são iguais? recrutamento legislativo em Brasil, Chile e Uruguai". Revista Brasileira de Ciências Sociais, v. 22, n. 64, pp. 93-113.

MAYHEW, David. (1974), Congress: The electoral connection. New Haven: Yale University Press.

MCCRARY, Justin. (2008), "Manipulation of the running variable in the regression discontinuity design: A density test". Journal of Econometrics, v. 142, n. 2, pp. 698-714.

MORGAN, Stephen; WINSHIP, Christopher. (2014), Counterfactuals and causal inference. Cambridge: Cambridge University Press.

PEREIRA, Carlos; RENNÓ, Lúcio. (2001), "O que é que o reeleito tem? dinâmicas políticoinstitucionais locais e nacionais nas eleições de 1998 para a Câmara dos Deputados". DADOS - Revista de Ciências Sociais, v. 44, n. 2, pp. 133-172.

. (2007), “O que é que o reeleito tem? O retorno: o esboço de uma teoria da reeleição no Brasil". Revista de Economia Política, v. 27, n. 4, pp. 664-683.

. (2013), "'Should I stay or should I go?' Explaining political ambition by electoral success in Brazil". Journal of Politics in Latin America, v. 5, n. 3, pp. 73-95.

PERISSINOTTO, Renato; MIRÍADE, Angel. (2009), "Caminhos para o parlamento: candidatos e eleitos nas eleições para deputado federal em 2006". DADOS - Revista de Ciências Sociais, v. 52, n. 2, pp. 301-333.

RUBIN, Donald. (1974), "Estimating causal effects of treatments in randomized and nonrandomized studies". Journal of Educational Psychology, v. 66, n. 5, pp. 688-701.

SAMUELS, David. (2000), "Ambition and competition: Explaining legislative turnover in Brazil". Legislative Studies Quarterly, v. 25, n. 3, pp. 481-497. 
SAMUELS, David. (2001), "Incumbents and challengers on a level playing field: Assessing the impact of campaign finance in Brazil". The Journal of Politics, v. 63, n. 2 , pp. 569-584.

(2003), Ambition, federalism, and legislative politics in Brazil. Cambridge: Cambridge University Press.

. (2008), "Political ambition, candidate recruitment, and legislative politics in Brazil". In: P. Siavelis; S. Morgenstern (eds.), Political Recruitment and Candidate Selection in Latin America. Pennsylvania: The Pennsylvania State University Press, pp. 76-91.

SANTOS, Fabiano; PEGURIER, Fabiano. (2011), “Political careers in Brazil: Long-term trends and cross-sectional variation". Regional and Federal Studies, v. 21, n. 2, pp. 165-183.

SEKHON, Jasjeet. (2009), “Opiates for the matches: Matching methods for causal inference". Annual Review of Political Science, v. 12, pp. 487-508.

SILVA, Glauco Peres da. (2017), "Mesmas instituições, mesmos resultados? Comparando o efeito da competição eleitoral sobre os níveis de concentração de votos". Opinião Pública, v. 23, n. 3, pp. 682-713.

SPECK, Bruno; MANCUSO, Wagner. (2014), "A study on the impact of campaign finance, political capital and gender on electoral performance". Brazilian Political Science Review, v. 8, n. 1, pp. 34-57. 


\section{RESUMO}

\section{Carreiras Politicas na Câmara dos Deputados: Uma Análise Quase-Experimental}

Este artigo investiga o efeito das eleições sobre as carreiras dos candidatos a deputado federal no Brasil. Com um desenho de regressão descontínua, ele mostra que os resultados de uma única eleição têm impactos substantivos na carreira parlamentar: obter um mandato na Câmara causa um aumento de cerca de 25 pontos percentuais a mais na chance de um político ser reeleito quatro anos depois, efeito que permanece positivo por até 12 anos após o primeiro mandato. Candidatos derrotados, ao contrário, passam a ambicionar mais cargos eletivos nos municípios, mas não têm maiores chances de obtê-los e, além disso, também têm probabilidade muito maior de se retirarem da arena eleitoral. Nesse sentido, o artigo contribui ao mostrar que os resultados de uma única eleição afetam decisivamente as perspectivas de carreira dos políticos brasileiros.

Palavras-chave: carreiras políticas; Câmara dos Deputados; vantagem dos incumbentes; reeleição; regressão descontínua

\section{ABSTRACT \\ Political Careers in the House of Representatives: A Quasi-Experimental Analysis}

This article investigates the effect of elections on the careers of federal deputy candidates in Brazil. Following a regression discontinuity design, it shows that the results of a single election have substantial impacts on parliamentary careers: obtaining a seat in the House results in an increase of about 25 percentage points in the chance of a politician being reelected four years later. This effect remains positive for up to twelve years after the first term. Defeated candidates, by contrast, tend to aim for more elective office positions in the municipalities, but are not only less likely to obtain them, but also much more likely to completely withdraw from the electoral arena. In this context, the article contributes by showing that the results of a single election decisively affect the career prospects of Brazilian politicians.

Keywords: political careers; House of Representatives; incumbency advantage; reelection; discontinuous regression 


\section{RÉSUMÉ \\ Carrières politiques Dans la Câmara dos Deputados: Une Analyse Quasi Expérimentale}

Cet article examine les conséquences des élections sur la carrière des candidats fédéraux au Brésil. S’appuyant sur un schéma de régression discontinu, on montre que les résultats d'une seule élection ont des conséquences importantes sur les carrières parlementaires: l'obtention d'un siège à la Chambre augmente de 25 points de plus les chances qu'un politicien soit réélu quatre ans plus tard, effet qui reste positif jusqu'à douze ans après le premier mandat. Les candidats battus, en revanche, visent un plus grand nombre de postes électifs dans les municipalités, mais ne sont pas plus susceptibles de les obtenir et sont également beaucoup plus susceptibles de se retirer de la scène électorale. En ce sens, l'article contribue en montrant que les résultats d'une élection unique affectent de manière décisive les perspectives de carrière des hommes politiques brésiliens.

Mots-Clés: carrières politiques; Câmara dos Deputados, avantage des titulaires; réélection; régression discontinue.

\section{RESUMEN}

Carreras Políticas en la Cámara de los Diputados: Un Análisis Cuasi experimental

Este artículo investiga el efecto de las elecciones sobre las carreras de los candidatos a diputado federal en Brasil. Con un diseño de regresión discontinua, se muestra que los resultados de una única elección tienen impactos sustantivos en la carrera parlamentaria: obtener un mandato en la Cámara causa un aumento de cerca de 25 puntos porcentuales de que un político tenga más oportunidad de ser reelegido cuatro años después, efecto que permanece positivo por hasta doce años después del primer mandato. Candidatos derrotados, por el contrario, pasan a ambicionar más cargos electivos en los municipios, pero no tienen mayores oportunidades de obtenerlos y, además de eso, también tienen probabilidad mucho mayor de retirarse de la arena electoral. En ese sentido, el artículo contribuye a mostrar que los resultados de una única elección afectan decisivamente las perspectivas de carrera de los políticos brasileros.

Palabras clave: carreras políticas; Cámara de Diputados; ventaja de los políticos titulares; reelección; regresión discontinua 